\title{
Modeling and Control of Torsional Vibration in Rotating System Using Dual Loop Controllers
}

\author{
Mustafa Mohammed Matrood*1, Ameen Ahmed Nassar ${ }^{2}$ \\ ${ }^{1}$ Engineering Maintenance Division, Mechanics Department, Basra Oil Company, Basra, Iraq \\ ${ }^{2}$ Department of Mechanical Engineering, College of Engineering, University of Basrah, Basra, Iraq
}

\author{
Correspondence \\ * Mustafa Mohammed Matrood \\ Engineering Maintenance Division, Mechanics Department, \\ Basra Oil Company, Basra, Iraq \\ Email: mtdmst83@gmail.com
}

\begin{abstract}
A torsional rotating system is considered for the investigation of passive vibration control using dual loop controllers Proportional-Integral-Derivative (PID) with derivative (D) gain and Proportional - Derivative (PD) with Integral (I) controllers. The controllers are used as low pass filters. Simulation of the models using Matlab-Simulink have been built in this work for torsional vibration control. A comparison between the two controllers with uncontrolled system have been carried out. Results show that the PD - I control is the best method which gives better stability response than the PID - D control. KEYWORDS: Dual Loop, PID, Rotating System, Torsional Vibration.
\end{abstract}

\section{INTRODUCTION}

Torsional rotating systems (TRS) are machines with elastic parts which respond to internal and/or external force/torque sources with some deflection. Torsional vibration is presented in such systems due to the interaction of those forces. Some internal sources are produced by the main electric motor, torque pulsations and inertia forces at shaft ends while some external sources are come from variable loading conditions or load disturbances. However, there effects on the entire system can be controlled by adding some torsional vibration absorbers. Other controlling methods can be achieved by reconstructing of certain controllers to stabilize most oscillations. Jun-Keun and Seung-Ki Sul (1995) [1] studied and proposed high-performance speed control for torsional vibration suppression in a 2-mass motor drive system. The performance of command following, torsional vibration suppression and robustness to parameter variation was satisfied by using Kalman filter and LQ based speed control with an integrator. Also disturbance rejection performance was improved. Fujikawa Kobayashi (1998) [2] proposed a torque control method of Two-Mass Resonant System with PID-P controller. The proposed controller consists of a PID controller with smaller gains and a $P$ feedback compensation of the shaft torque using a torque meter. Qiao, etal. (2002) [3] studied the vibration suppression and the disturbance rejection of the 2 - mass main d rive system in rolling mill of a steel works with Kalman filter enhanced state feedback pole placement controller. The simulation results showed that the proposed controller improved the transient behavior of the system. Szabat and Orlowska-Kowalska (2007) [4] used an analysis of control structures for the electrical drive system with elastic joint. The control structure with proportional-integral controller supported by different additional feedbacks was presented. The classical pole-placement method was applied. In order to damp the torsional vibration effectively, the application of the feedback from one selected state variable was necessary. The system with two additional feedbacks was also investigated. Shahgholian, etal. (2009) [5] presented an algorithm to design a speed control strategy of a two-mass resonant system for torsional vibration suppression and attainment of robustness in motion control systems by a proportional- integral derivative (PID) controller. The simulation results showed that the control method had robust stability and fast speed response. Yousefi, etal. (2010) [6] presented a speed control strategy for the torsional vibration systems. A state feedback control law using an integrator was designed. The simulation results were shown to verify good performance obtained using the proposed controller.

Ghazanfar, etal. (2011) [7] suggested a modified PID controller to improve the dynamic Performance of a two-mass system using speed controller and compared with only PID controller. The dynamic analysis is verified by transfer function simulation using Matlab and time domain 
simulation of the two-mass system. It is seen that the control system has fast speed response and robust stability. Ekhlas Hameed Karam [8] (2013) suggested a simple and efficient hybrid PID with simple fuzzy controller (FC) in order to improve the performance of the different PID controllers. The suggested method applied on single link flexible joint robot. The new hybrid connection PID-FC methods make the output response of the tested plant more accurate in tracking the desired input with zero or very small steady state error. Shahgholian, etal. (2014) [9] presented a speed control strategy for the torsional vibration systems. The state feedback strategy with integral control based on the detailed small-signal model was applied to design the speed controller for the two-mass resonant system. The integral control exhibited no steady state error in the response to the step input. Korkmaz, etal. (2014) [10] used the modified Proportional-Integrative-Derivative control system to enhance the performance of the ship shaft control system and to adjust the torsional vibration. The performance of the traditional PID controller was improved by moving derivative and proportional blocks on feedback path. In this study, main motor, shaft and inertial load system were modeled by Newton's Second law, and the model was simulated by using Matlab-Simulink software. Torsional vibration analysis was confirmed because of the resulting risk.

The goal of this research is to reduce system oscillations by controlling shaft torsional vibration through the application of certain dual loop controllers such as PID - D and PD - I. A comparison showed that PD - I controller made better stability response than PID - D controller. This research is organized as follows:

In section II, the torsional rotating system model is derived. The PID $-\mathrm{D}$ and PD - I dual loop controllers are proposed. In section III. Simulation and control results are deduced in section IV. Finally, conclusions are presented in section $\mathrm{V}$.

\section{MATHEMATICAL MODELING OF TORSIONAL ROTATING SYSTEM}

A two degree of freedom (2DOF) torsional rotating system is considered which consists of electric motor, shaft and load. The analysis is based on equation of motion derived from Newton's Second law of motion as "The sum of applied torques is equal to the inertia forces". The equation of motion for 2DOF rotating system is inserted after drawing Free-body diagram. Fig. 1 shows the physical model of torsional rotating system. The free body diagram is drawn in Fig. 2.

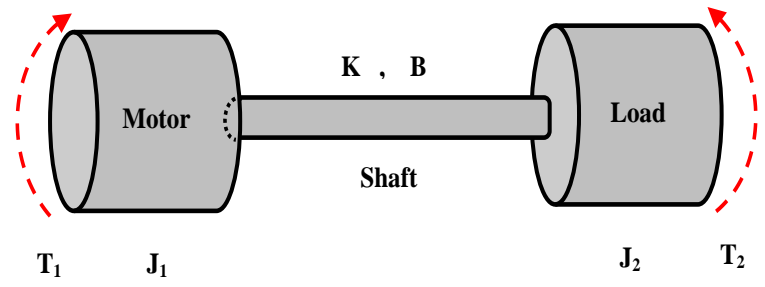

Fig. 1: Physical model of torsional system

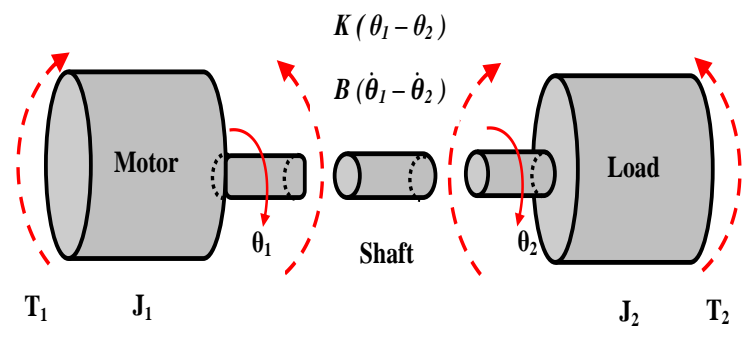

Fig. 2: Free body diagram of torsional system

For motor:

$$
\mathrm{J} \ddot{\theta}=\sum \mathrm{T}
$$

For load:

$$
\mathrm{J}_{1} \ddot{\theta}_{1}=\mathrm{T}_{1}-\mathrm{K} \theta_{1}-\mathrm{B} \dot{\theta}_{1}+\mathrm{K} \theta_{2}+\mathrm{B} \dot{\theta}_{2}
$$

$$
\mathrm{J}_{2} \ddot{\theta}_{2}=\mathrm{K} \theta_{1}+\mathrm{B} \dot{\theta}_{1}-\mathrm{K} \theta_{2}-\mathrm{B} \dot{\theta}_{2}-\mathrm{T}_{2}
$$

Rearranging the above equations yields:

$$
\begin{gathered}
\mathrm{J}_{1} \ddot{\theta}_{1}=\mathrm{T}_{1}-\mathrm{K}\left(\theta_{1}-\theta_{2}\right)-\mathrm{B}\left(\dot{\theta}_{1}-\dot{\theta}_{2}\right) \\
\mathrm{J}_{2} \ddot{\theta}_{2}=\mathrm{K}\left(\theta_{1}-\theta_{2}\right)+\mathrm{B}\left(\dot{\theta}_{1}-\dot{\theta}_{2}\right)-\mathrm{T}_{2}
\end{gathered}
$$

Where:

$\mathbf{J}_{1}$ and $\mathbf{J}_{2}$ we polar mass moment of inertia of motor and load respectively. $\mathrm{K}$ and $\mathrm{B}$ are shaft stiffness inherent damping. $\mathrm{T}_{1}$ and $\mathrm{T}_{2}$ are motor and load torques respectively. $\theta_{1}$ and $\theta_{2}$ are the angles of motor and load respectively. $\theta_{1}-\theta_{2}$ is Shaft twist.

When torque is applied to a mass it will begin to accelerate, in rotation. When the system starts rotation the motor will generate some torque which transmits through the shaft to the load which in $t$ urn will accelerate the system as a result of continues rotation until approaches to the required constant speed.

This torque has noise components which increase as the deformation increases. When combining the torsional rotating system with a feedback system, the frequencies of the entire system can be interacted causing high frequency noise which in turn can produce more torsional oscillations through the system [11].

\section{DUAL LOOP CONTROLLER (DLC)}

The two main controllable variables related to the torsional vibration in this study are $\theta_{1}$ and $\theta_{2}$ associated with the terminal points at $\mathbf{J}_{1}$ and $\mathbf{J}_{2}$ to form a complete mechanical network. This controller uses two feedback sensors. The advantages of this controller is to reach the control law or the feedback signal to the system as a filtered signal without noise and torque components. DLC can be constructed by using two feedback signal devices forming two loops, one of them is the inner loop while the other represents the outer loop. The inner loop connected to the output of motor velocity or position with either derivative controller (D) with a suitable gain or proportional - derivative controller (PD) so it acts like a low pass filter while the outer loop is the normal feedback controlled signal with conventional (PID) controller [8] or (I) controller [12] respectively to accumulate a position error moving away any inaccuracy in the transmission part, thereby assuring system accuracy and 
stability. Fig. 3 and Fig.4 show block diagrams for (PID - D) and (I - PD) dual loop controllers respectively.

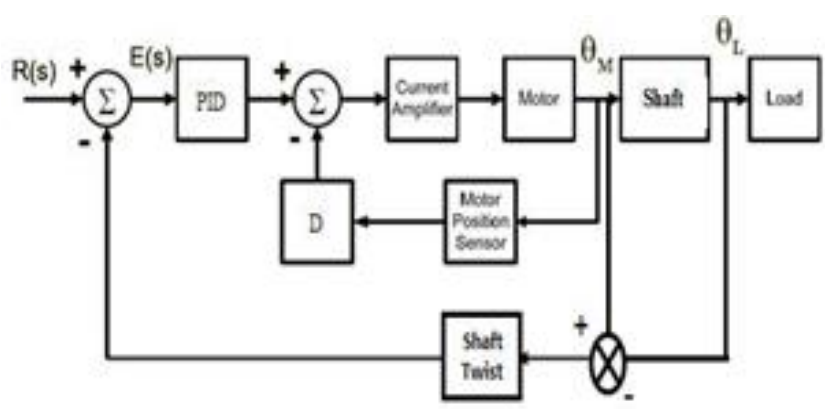

Fig. 3: Dual-loop PID-D controller

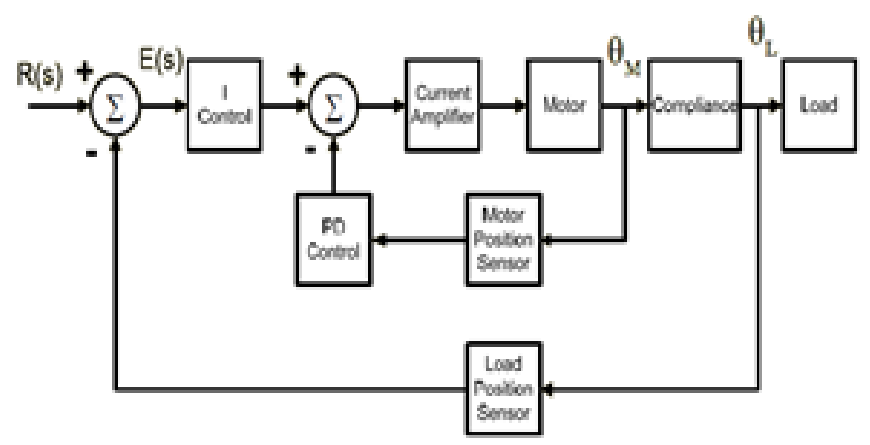

Fig. 4: Dual-loop I-PD controller

\section{SiMULATION AND RESULTS}

The main uncontrolled system was analyzed with (PID - D) and (I - PD) dual loop controllers structures. In order to verify the effectiveness of the simulations, the specific parameters of the system are listed in Table 1. Depending on the mathematical model given in section 2, the Matlab / Simulink model for (2DOF) rotating system using a unit step function input signal as an excitation is shown in Fig. 5.

TABLE 1

SYSTEM PARAMETERS OF THE MODEL [5]

\begin{tabular}{|l|c|}
\hline $\begin{array}{l}\text { Polar mass moment of inertia } \\
\text { of the driving motor }\left(\mathrm{J}_{1}\right)\end{array}$ & $0.0641 \mathrm{~kg} \mathrm{~m}^{2}$ \\
\hline $\begin{array}{l}\text { Polar mass moment of inertia } \\
\text { of the driven object }\left(\mathrm{J}_{2}\right)\end{array}$ & $0.0523 \mathrm{~kg} \mathrm{~m}^{2}$ \\
\hline Shaft stiffness ( K ) & $242 \mathrm{Nm} / \mathrm{rad}$ \\
\hline Shaft damping ( B ) & $0.15 \mathrm{Nms} / \mathrm{rad}$ \\
\hline
\end{tabular}

The simulation of (2DOF) rotating system is performed in Matlab / Simulink in order to show the behavior and the effectiveness of such system when applying torque and by knowing the angle of twist the applied torque can be modulated for tuning the variation in twist angles.

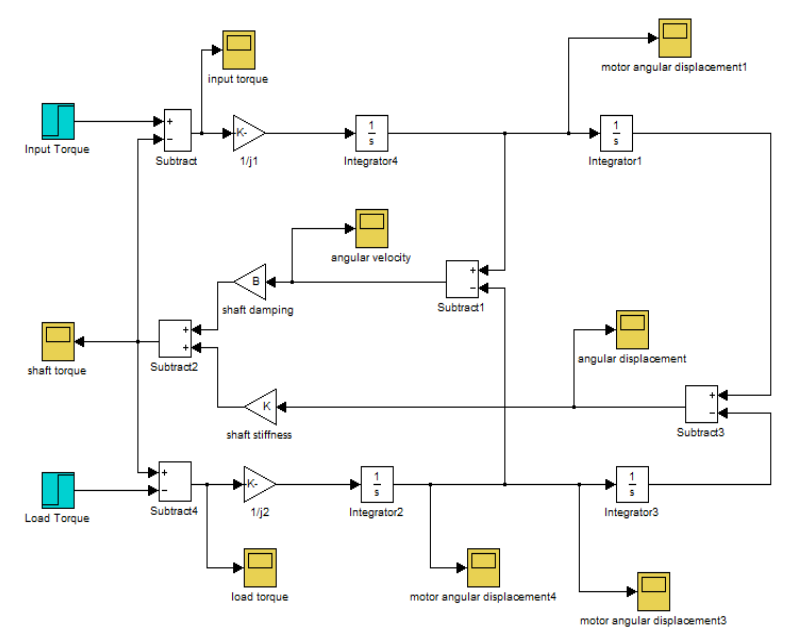

Fig. 5: Simulink module of (2DOF)

The principle of (PID - D) controller is achieved by adding suitable gain to the motor position feedback. In this study, a derivative gain with a value about 6 is applied to insure good damping and stability with the aid of conventional PID controller as shown in Fig. 6. This controller provides double loops to control system variables. The PID controller parameters are selected by trial and error procedure as: $\mathrm{Kp}=0.001, \mathrm{~K}_{\mathrm{I}}=0.0004, \mathrm{~K}_{\mathrm{D}}=0.001$.

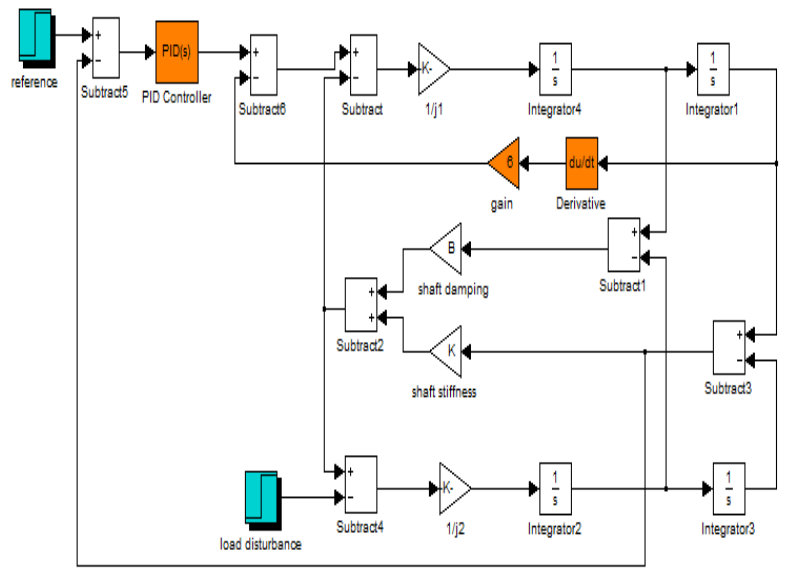

Fig. 6: Simulink module of (2DOF) rotating system with PID-D controller

The second type of dual loop controller is constructed by using motor position feedback inner loop with PD controller and remaining the feed forward I controller. The Simulink model is built as illustrated in Fig. 7. Referring to the Fig. 7, the inner loop PD parameters are selected as 50 and 5 respectively while the I controller parameter is chosen as 0.1 . 


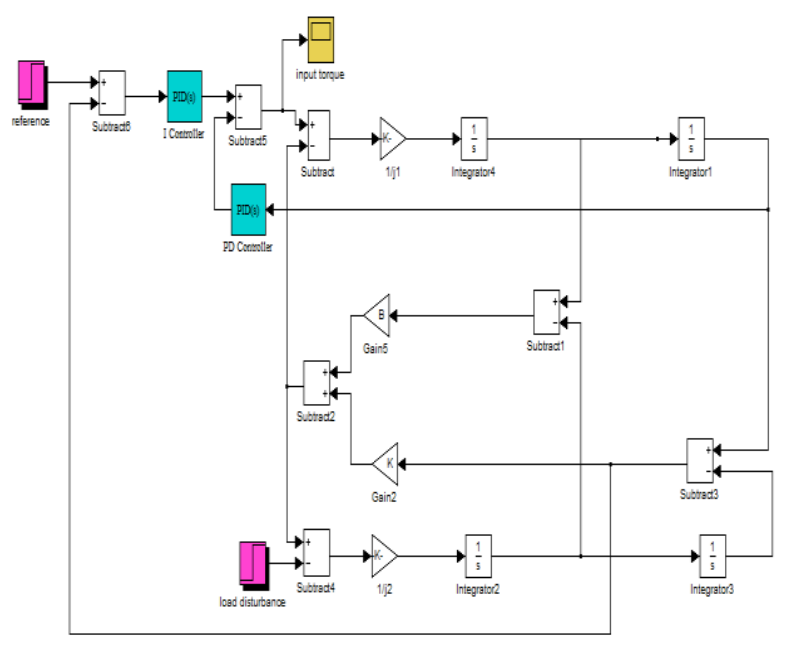

Fig. 7: Simulink Implementation of (2DOF) rotating system with $(\mathrm{PD}-\mathrm{I})$ dual loop controller

For the purpose of comparing the results, the uncontrolled system will be simulated with PID - D and I - PD controlled system in order to show the summary of response among the system torsional state variables. Fig. 8 shows the Simulink model implemented for the comparisons while Fig. 9 illustrates the response belonging to it which shows that the I - PD controller proposed in this work gave the best response by eliminating most aliasing and oscillations in the original system. Table 2 illustrates the parametric results and the effects of such controllers on the system response.

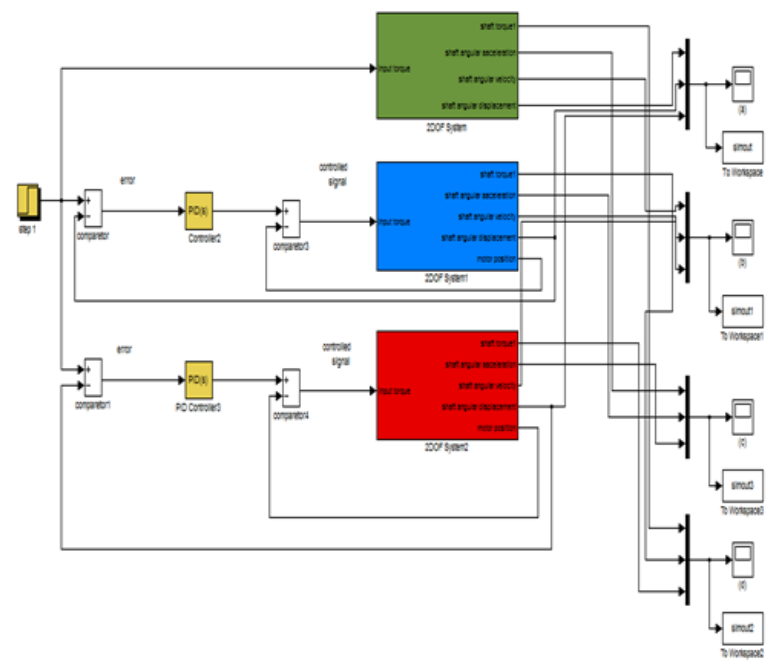

Fig. 8: Simulink model of 2DOF torsional system for comparison purposes

The subsystems represent the torsional system as implemented in Figure 5, the green, dashed line shows the response of uncontrolled system while the blue and red lines indicate the response of PID - D and I - PD controlled system respectively.

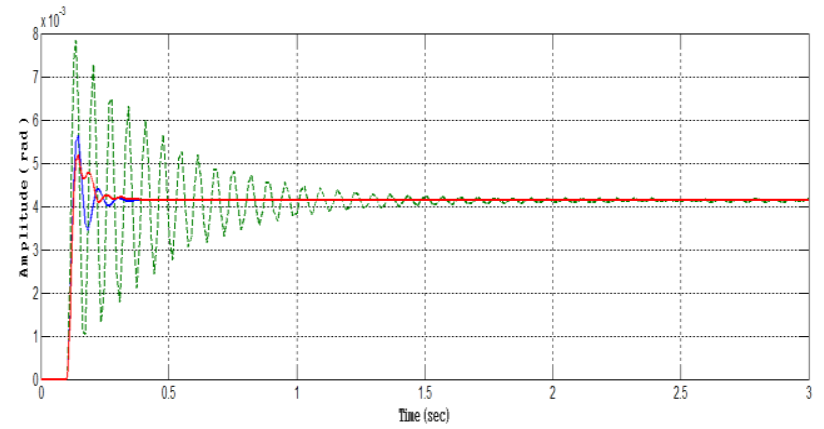

(a)

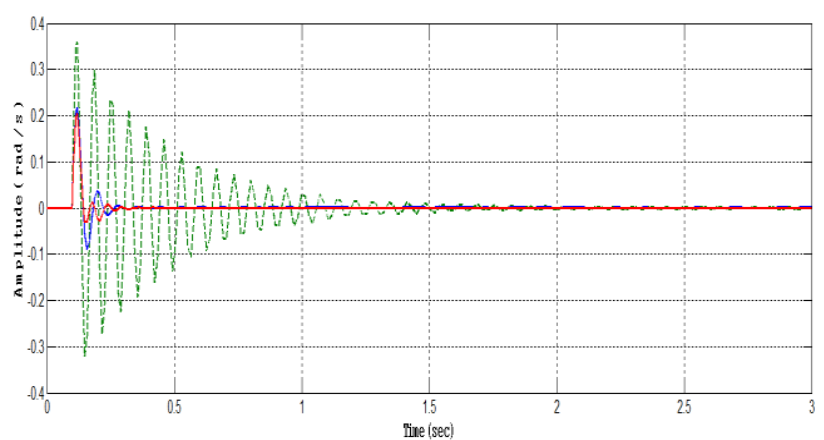

(b)

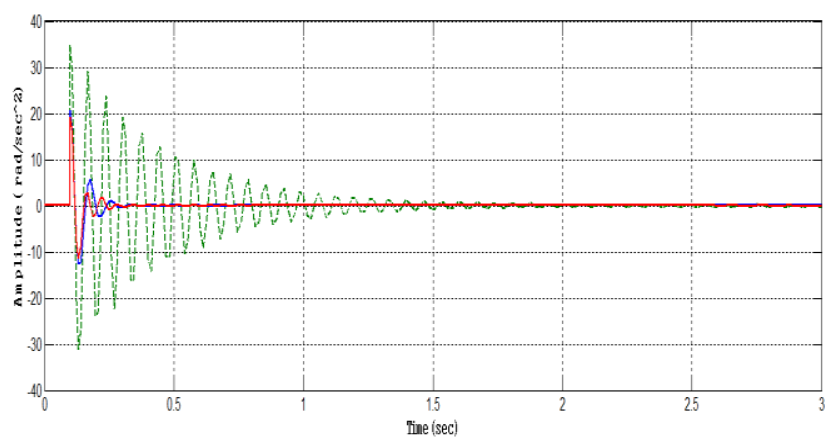

(c)

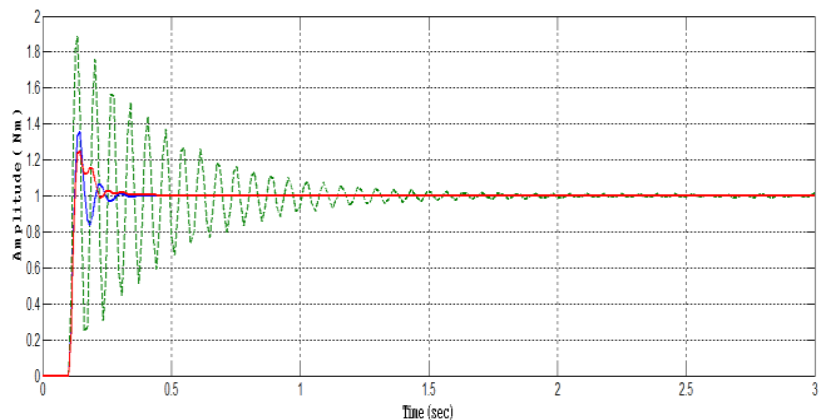

(d)

Fig. 9: Response comparisons of 2DOF torsional system (a) angular displacement, (b) angular velocity, (c) angular acceleration,(d) shaft torque 
TABLE 2

PARAMETRIC RESULTS BEFORE AND AFTER ADDING PID-D AND I-PD CONTROLLERS TO THE 2DOF TORSIONAL SYSTEM

\begin{tabular}{|c|c|c|c|}
\hline System & Property & Amplitude & $\begin{array}{l}\text { Settling Time } \\
\text { (second) }\end{array}$ \\
\hline \multirow{4}{*}{ Uncontrolled } & $\Delta \theta \quad(\mathbf{r a d})$ & $7 * 10^{-3}$ & 1.5 \\
\hline & $\Delta \dot{\theta} \quad(\mathrm{rad} / \mathrm{s})$ & 0.66 & 1.5 \\
\hline & $\Delta \ddot{\theta} \quad\left(\mathrm{rad} / \mathrm{s}^{2}\right)$ & 66 & 1.5 \\
\hline & $\mathrm{T}_{\mathrm{s}} \quad(\mathrm{Nm})$ & 1.7 & 1.5 \\
\hline \multirow{4}{*}{$\begin{array}{l}\text { PID-D } \\
\text { Controller }\end{array}$} & $\Delta \theta \quad($ rad $)$ & $2.13 * 10^{-3}$ & 0.2 \\
\hline & $\Delta \dot{\theta} \quad(\mathrm{rad} / \mathrm{s})$ & 0.305 & 0.2 \\
\hline & $\Delta \ddot{\theta} \quad\left(\mathrm{rad} / \mathrm{s}^{2}\right)$ & 33.5 & 0.2 \\
\hline & $\begin{array}{ll}\mathrm{T}_{\mathrm{s}} & (\mathrm{Nm})\end{array}$ & 0.57 & 0.2 \\
\hline \multirow{4}{*}{$\begin{array}{c}\text { I-PD } \\
\text { Controller }\end{array}$} & $\Delta \theta \quad(\mathbf{r a d})$ & $1.05 * 10^{-3}$ & 0.13 \\
\hline & $\Delta \dot{\theta} \quad(\mathbf{r a d} / \mathbf{s})$ & 0.233 & 0.15 \\
\hline & $\Delta \ddot{\theta} \quad\left(\mathrm{rad} / \mathrm{s}^{2}\right)$ & 29.85 & 0.2 \\
\hline & $\mathrm{T}_{\mathrm{s}} \quad(\mathrm{Nm})$ & 0.25 & 0.12 \\
\hline
\end{tabular}

\section{Conclusions}

In this study, an investigation of the reasons causing oscillations and instability in 2-DOF torsional rotating system "motor, transmission part and load" has been presented with the existence of load disturbance torque. Newton's second law was used to derive the mathematical model of the dynamic system. It has been deduced throughout the previous explanation that there are many of instability sources, some of them mechanical such as inertia mismatch, shaft stiffness and shaft damping while others are electrical like pulsations associated with the torque generated by the motor and noise initiated due to positioning of single loop sensors. It was shown that the position of a feedback sensor has great effect, using single loop feedback circuit made the system unstable; however; oscillations may be introduced due to the difference in the load response as a result of twisted shaft. Placing dual loop feedback sensors on both motor and load sides took the flexibility of shaft into account. Such controllers gave minimum oscillations, overshot has been decreased, smoother steady state and good transient responses with high accuracy. As a result, it is clear that with the dual loop control, a good performance has been achieved. As indicated in Table 2, the time taken for the main system to settle for the steady state with PID - D and I - PD controllers has been reduced to about $13 \%$ and $10 \%$ respectively from the entire time taken by the uncontrolled system which means faster steady state approach. In addition the other referred parameters have been improved by reducing the corresponding values.

\section{CONFLICT OF INTEREST}

The authors have no conflict of relevant interest to this article.

\section{REFERENCES}

[1] Jun-Keun Ji Seung-Ki Sul, "Kalman Filter and LQ Based Speed controller for Torsional Vibration Suppression in 2-Mass Motor Drive System ", IEEE Transactions on Industrials Electronics, vol. 42, No. 6, 1995.

[2] Y. Wu, K. Fujikawa, and H. Kobayashi , “ A torque control method of two-mass resonant system with PID-P controller," in Proc. Int. Workshop AMC, Coimbra, pp. 240-245, 1998.

[3] F. Qiao, Q.M. Zhu, S.Y. Li, and A. Winfield, " Torsional Vibration Suppression of a 2-Mass Main Drive System of Rolling Mill with KF Enhanced Pole Placement ", IEEE Proceedings of the $4^{\text {th }}$ World Congress on Intelligent Control and Automation, 2002.

[4] K. Szabat and T. Orlowska-Kowalska, " Vibration suppression in two-mass drive system using PI speed controller and additional feedbacks Comparative study ," IEEE Trans. Ind. Electron., vol. 54, no. 2, pp. 1193-1206, 2007.

[5] Gh. Shahgholian, J. Faiz, P. Shafaghi, "Analysis and Simulation of Speed Control for Two-Mass Resonant System”, IEEE/ICCEE, pp. 668-672, 2009.

[6] M.R. Yousefi, Gh. Shahgholian, A. Etesami,P. Shafaghi, "Small Signal Modeling and Analysis of Control Speed for Two Mass Resonant System", IEEE/IPEC, pp. 1000-1003, 2010.

[7] Ghazanfar Shahgholian, Afshin Etesami, Mohammad Reza Yousefi and Farshad Mogharrab Tehrani, " Development of State Space Model and Control Design of Two - Mass System Using Standard Forms ",

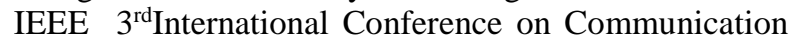
Software and Networks, 2011.

[8] Ekhlas Hameed Karam," Hybrid Connection of PID and Fuzzy Controller for Flexible Joint Robot with Uncertainties", Journal of Engineering and Development, Vol. 17, No.5,ISSN1813-7822, 2013.

[9] Gh. Shahgholian, P. Shafaghi, Z. Azimi, " State space model and speed control of two-mass resonant system using state feedback design ", International Journal on Technical and Physical Problems of Engineering, Vol. 6, No.2, PP.111-116, 2014.

[10] Fatih Cüneyd [10] Korkmaz, Muhammet Ertuğrul Su, Fuat Alarçin," Control of Ship Shaft Torsional Vibration Via Modified PID Controller", Brodogradnja/Shipbuilding, Vol. 65, No. 1, PP. 17-27, 2014.

[11] Slobodan N. Vukosavic,"Digital Control of Electrical Drives", Springer Science, 978-0-387-48598-0, 2007.

[12] George Ellis, "Control System Design Guide", Elsevier Academic Press, Third Edition, 0-12-237461-4, 2004. 